
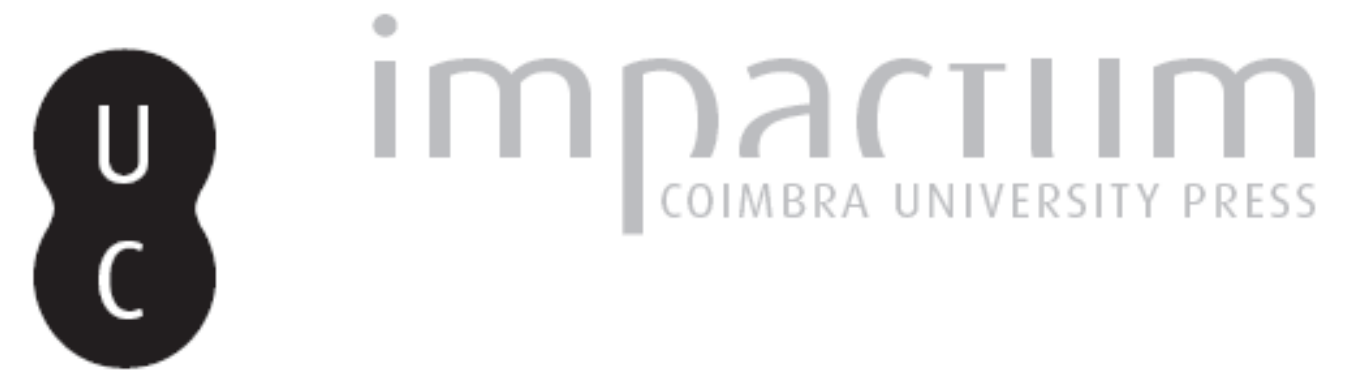

\title{
O mito e o rito: aspectos rituais nos Epinícios de Píndaro
}

\author{
Autor(es): $\quad$ Gimenes Romero, Sérgio Luiz Gusmão
}

Publicado por: Sociedade Brasileira de Estudos Clássicos

URL persistente:

URI:http://hdl.handle.net/10316.2/37146

DOI:

DOI:http://dx.doi.org/10.14195/2176-6436_26-2_5

Accessed : $\quad$ 26-Apr-2023 14:50:27

A navegação consulta e descarregamento dos títulos inseridos nas Bibliotecas Digitais UC Digitalis, UC Pombalina e UC Impactum, pressupõem a aceitação plena e sem reservas dos Termos e Condições de Uso destas Bibliotecas Digitais, disponíveis em https://digitalis.uc.pt/pt-pt/termos.

Conforme exposto nos referidos Termos e Condições de Uso, o descarregamento de títulos de acesso restrito requer uma licença válida de autorização devendo o utilizador aceder ao(s) documento(s) a partir de um endereço de IP da instituição detentora da supramencionada licença.

Ao utilizador é apenas permitido o descarregamento para uso pessoal, pelo que o emprego do(s) título(s) descarregado(s) para outro fim, designadamente comercial, carece de autorização do respetivo autor ou editor da obra.

Na medida em que todas as obras da UC Digitalis se encontram protegidas pelo Código do Direito de Autor e Direitos Conexos e demais legislação aplicável, toda a cópia, parcial ou total, deste documento, nos casos em que é legalmente admitida, deverá conter ou fazer-se acompanhar por este aviso.

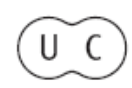




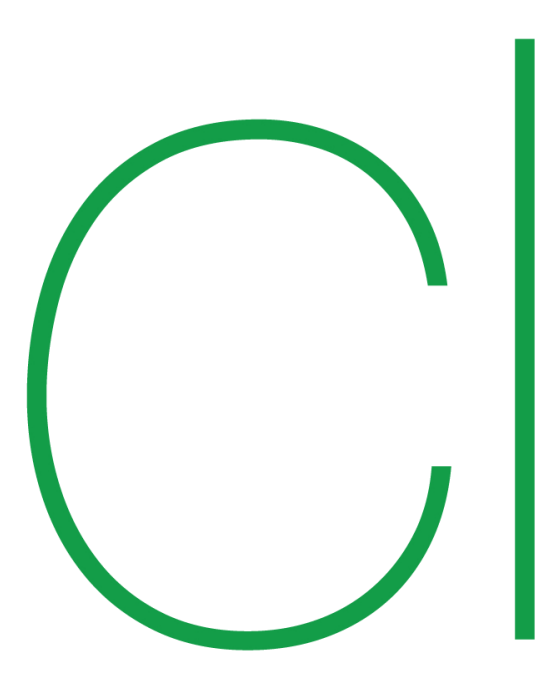

revista brasileira de estudos clássicos
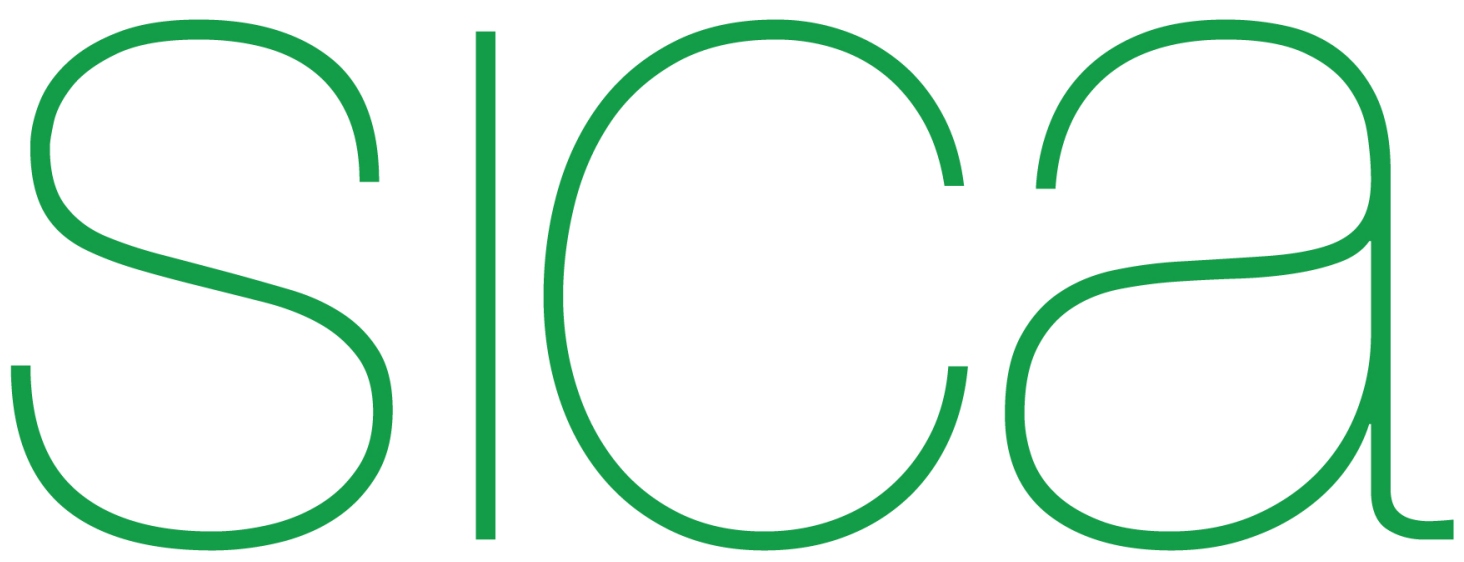

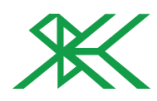

y

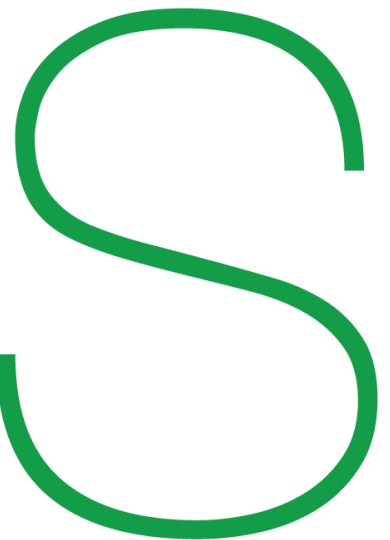




\section{O MITO E O RITO: ASPECTOS RITUAIS NOS EPINÍCIOS DE PÍNDARO}

RESUMO: O presente trabalho apresenta uma reflexão acerca da dimensão performática dos epinícios de Píndaro, analisando a dinâmica estabelecida por mito e ritual no contexto da performance. A Olimpica I constitui o foco do trabalho e, desse modo, apresenta-se uma breve análise com vistas ao delineamento da conjuntura mito-ritualística que lhe é própria, bem como das características e sentidos que a projeção de sua performance suscita.

PALAVRAS-CHAVE: Píndaro. Olimpica I. Performance. Mito. Ritual.

ABSTRACT: This paper presents a reflection on the performative dimension of epinician odes of Pindar, analyzing the dynamics established by myth and ritual in the context of performance. The Olympian I is the focus of the work and thus presents a brief analysis with a view to delineate the myth-ritual scenario which is its feature, as well as the characteristics and senses that the projection of their performance raises.

KEYWORDS: Pindar. Olympic I. Performance. Myth. Ritual. 
Um conhecido problema da crítica pindárica parece advir da dificuldade de se encontrar um fio condutor que oriente a construção de uma leitura válida da obra de Píndaro que, por um lado, não ignore a conjuntura e as circunstâncias de sua poesia laudatória, mas que, por outro lado, não a absolutize em detrimento dos aspectos e valores estéticos, poéticos e míticos.

De fato, parece ser fundamental e produtivo, ante a complexidade da ode epinícia de Píndaro, que se considere o conteúdo das composiçóes, com seus mitos e aspectos reflexivos e simbólicos tão característicos, mas, no entanto, para que se possa construir uma leitura crítico-interpretativa que melhor apreenda os sentidos estabelecidos na poesia pindárica, faz-se necessário analisar, também, a situação da celebração que veicula esses conteúdos. Tomando como chave de leitura a sua dimensão de performance ritualizada, podemos projetar em nossa compreensão do epinício a dinâmica e o valor que ele estabeleceu com a conjuntura que lhe era própria no universo da Grécia arcaica.

Para tanto, convém que se reflita e se problematize, em relação à poética de Píndaro, a relação que se estabelece entre mito, rito e performance.

O mito em Píndaro constitui o mais denso substrato na composição de suas odes aos vencedores dos jogos atléticos. Através da leitura de seus epinícios temos acesso às mais variadas narrativas míticas esteticamente trabalhadas. No entanto, convém que se pontue que a percepção desses mitos enquanto material de leitura está aquém de sua perspectiva original performatizada, articulada dentro de um contexto de celebraçáo e nele engajada.

Com efeito, segundo Claude Calame (1997), o mito, na tradição cultural da Grécia antiga, só toma forma na instância na qual é enunciado. $\mathrm{O}$ mito:

existe somente nas formas poéticas que tornam as narrativas eficazes junto a um público ativo em dadas circunstâncias rituais, sociais e culturais. Ou seja, todo enunciado mítico depende de regras (verbais e sociais) do gênero poético que o corporifica em enunciação, em condiçóes particulares. (idem, p. 52).

Assim, a eficácia do mito, no contexto da poesia mélica grega, se apresenta irrevogavelmente vinculada à sua orquestração ritual (Kowalzig, 2007) e é através de sua inerente teatralidade que a narrativa mítica performatizada atua no con- 
texto social. O mito surge assim, como uma potencialidade que se atualiza a cada performance e é por meio deste processo que a comunidade vivencia a sua religiosidade.

Segundo Barbara Kowalzig (2007), o tipo de mito que mais intrinsicamente se relaciona com o ritual é o mito etiológico (do grego aitía: origem, princípio, causa). Os mitos etiológicos eram vitais para a vivência religiosa diária da comunidade, contavam a origem de ritos, costumes, cultos, templos, objetos de devoçáa e espaços sacralizados. A etiologia validava a prática religiosa local ao mesmo tempo em que a enquadrava em um quadro mitológico mais abrangente.

Segundo Kowalzig:

The institutions of Greek religion are almost all imagined to have been invented and authoritatively created in Eliade's famous illud tempus, in a timeless period of origins. This beginning has supreme authority, and linking oneself to the creative moment offers a share in this authority.

Aetiology thus by definition oscillates between mythical past and ritual present, and this circumstance is pivotal for its role in a social context. (KowaLzig, 2007, p. 24).

Assim, é desse passado mítico que advém a autoridade social que a etiologia exerce no presente. Uma autoridade alicerçada na sacralidade desse universo arquetípico e que pode, através da articulação criativa da enunciação do mito, ser compartilhada por aqueles que fazem parte do processo.

Contudo, o mito etiológico não emana de um passado absoluto, moldando, a partir dele, a realidade presente, mas, inversamente, manipula uma tradiçâo flexível e renovável dispondo dela segundo as demandas sociais, culturais e estéticas do hic-et-nunc de sua enunciação. De acordo com Barbara Kowalzig (2007, p. 29):

Aetiology acts out truths of the present in the mythical past, telling us a lot about the present in which it is being narrated and in which it is culturally relevant; about the past that it pretends to describe, however, it conveys very little.

Desse modo, a etiologia se vale da manipulação do tempo como estratégia para validar-se enquanto autoridade tradicional e atuar no contexto social. Ao contrário do que 
a própria palavra etiologia pode sugerir (motivo para algo ou a sua origem), o que se constata é uma lógica particular de atuação: "aetiology reduces the connecting of cause with effect to connecting mythical past directly with the present, thereby achieving a transcendence of time" (Kowalzig, 2007, p. 26).

Desconstrói-se, assim, a concepção do mito enquanto modelo rígido, tornando-se possível compreender a pluralidade de narrativas e versóes díspares dos mesmos mitos que convivem e se sobrepóem no universo grego arcaico. $\mathrm{O}$ aparentemente confuso quadro, em que por vezes vemos um mesmo mito ser contado de formas diferentes, confirma a maleabilidade da etiologia, comprovando a vinculação espacialmente restrita do mito etiológico que, com efeito, se apresenta como um conto local, atrelado a um evento singular ou localidade específica, com a presença de circunstâncias e fatos particulares.

A tradição remodela-se segundo as circunstâncias particulares de tempo e espaço. O mito é sensível ao que o transcorrer do tempo e a especificidade local lhe apresentam e, em uma perspectiva diacrônica, acompanha o presente apesar de projetar-se como algo essencialmente situado no passado.

$\mathrm{O}$ mito etiológico postula uma continuidade avessa ao desenrolar do tempo histórico. Uma tradiçẫo ininterrupta com a qual uma dada comunidade religiosa se identifica, mas que, de fato, se trata de uma representação.

Por sua vez, o ritual tem sido considerado pela antropologia moderna como um meio de acesso e análise dos valores, ideais e dinâmicas sociais de uma determinada comunidade. Barbara Kowalzig observa que a perspectiva dos estudos de análise de rituais modificou-se profundamente em sua abordagem e fornece uma definição teórica de como o ritual age sobre e interage com a sociedade:

The thinking about ritual has moved away from the idea that ritual is something fixed and inflexible towards a view that sees in ritual a dynamic and efficient element of social activity, firmly rooted in the present rather than the past. Rituals are constantly renewed and reformed in performance, oscillating as they are between ossification and creativity. A powerful tool for creating and maintaining social relations, ritual emerges as a medium for accommodating change. (Kowalzig, 2007, p. 34). 
A dinâmica do ritual não só instaura um senso de identidade coletiva como também atua sobre essa coletividade restabelecendo as inter-relaçóes e os papéis sociais à medida que eles vão se transformando. $\mathrm{O}$ ritual suscita um senso de comunidade através de uma estratégia paralela à do mito, ou seja, o ritual utiliza uma pretensa "antiguidade" tradicional como estratégia para atuar em termos de convencimento e aceitaçáo. Desse modo a configuração do ritual é sempre objetiva em relação aos seus fins:

Being old is an appearance of ritual, but more importantly it is a technique, something that ritual aspires to. All the characteristics of ritual are geared towards this goal-its formality, archaism, symbolism, repetition (KowaLzig, 2007, p. 34).

O epinício de Píndaro, tomado enquanto performance, enquadra-se perfeitamente no âmbito do ritual no que tange à sua dinâmica social. O coro é a representação por excelência de uma voz coletiva (CAREY, 2009, p. 23), que se insere em uma conjuntura particular de normas sociais e de gênero em um espaço-tempo específico. Assim, na celebração da vitória de um príncipe, em um dos Jogos Pan-helênicos, o canto projeta-se como uma representação da coletividade aristocrática, com seus valores e papéis sendo atualizados em relação à comunidade por meio da autoridade de um passado mítico que se quer sagrado.

De acordo com Bárbara Kowalzig (2007), o ritual pode constituir nada mais do que uma ritualização das relaçóes sociais contemporâneas através da tradicionalização, para construir uma comunidade de culto, como se ela derivasse de tempos antigos. Com efeito, quando relacionamos um mito contado por Píndaro em uma ode de vitória com aquele a quem ela se dedica, é difícil definir em que medida a figura do herói mítico recuperada da tradiçáo define os contornos da figura do vencedor ou vice-versa. Pois, porquanto se tenha dito que as circunstâncias definem a tradição, em detrimento de uma visão de mito e ritual inflexíveis, convém pontuar que essa é uma via de mão dupla e o presente também tem de ceder espaço à "tradiçãa" e ao que nela se deposita de valores e formas de pensamento.

Assim, nesse embate de perspectivas, ambos, presente e passado, têm de fazer concessóes: o presente tende a harmonizar-se com a tradição passada representada pelo mito, e o 
1. Cf. PELLICCIA, 2009, p. 254-255. passado mítico é remodelado de acordo com as exigências do presente. Destarte, mito e ritual estabelecem uma relação de interação na qual a tradição existe, mas é maleável.

Se, por um lado, a questão da constante transformação e renovação da tradição implica uma abordagem que considere a interação entre mito e ritual, por outro convém atentar para aquilo que constitui a principal característica do ritual: o fato de que ele náo é lido ou falado, mas encenado em uma performance (KowALZIG, 2007). É no contexto da "performance ritual do canto" (Calame, 1997, p. 62) que mito e ritual interagem, e é dessa conjuntura performativa que advém seu poder social.

Esse poder parece ser projetado a partir da dimensão estética que o ritual suscita através da performance. $\mathrm{O}$ desempenho ritual é assimilado muito mais por uma chave emocional-sensorial que racional. Isso pode sugerir uma tese explicativa, no mínimo interessante, para o fato de que os expectadores da performance de uma ode de Píndaro, presumivelmente, sentiam dificuldades em compreender intelectualmente a totalidade do discurso veiculado pelo canto, dada a complexidade da linguagem poética em dialeto dórico utilizada, a presença densa tanto de neologismos quanto de arcaísmos, bem como as mudanças surpreendentes na direção narrativa, etc ${ }^{1}$.

A respeito dessa abordagem Kowalzig afirma que:

(...) rituals are felt and experienced, not understood. At the basis of the definition of the register in which 'understanding' is generated through emotional and behavioural, rather than intellectual, involvement, lies the recognition that it is predominantly the simultaneous presence of many media in ritual, employed redundantly, that allows for aesthetic understanding and accounts for ritual's complex potential in society. Ritual's dramaturgy is intricate, often simultaneously employing elements such as role play and text, music, song, and dance. All of these are geared towards the same thing, though none of them acts in the same way as another, nor would any of them make the same sense if performed on their own. (KowaLzig, 2007, p. 47).

Assim, a poesia laudatória de Píndaro tomada em seu caráter performático, revela-se como uma confluência expressiva de melodia, gesto e palavra, e assume, no que tange à sua execução, os contornos operativos de uma celebração ritual. 
Mas o que aqui designamos como aspecto ritual não passa, obviamente, por uma definição rígida ou limitadora; quer-se, antes, como uma perspectiva operacional e maleável que permita abarcar nomeadamente o caráter performático do epinício de Píndaro.

A apresentação do canto pindárico, recuperada analiticamente a conjuntura que lhe é própria, conjuga uma série de linguagens com vistas a comunicar, dentro do espaço cultural específico a que pertence, valores e sentidos alicerçados em sua tradição mítica e compartilhados pela coletividade. Assim, a dinâmica estratégica já proposta de transcendência de tempo opera sobre a sociedade, permitindo a acomodaçãa de suas transformaçóes históricas e sua afirmação enquanto identidade social específica, capaz também de se perpetuar através das transformaçóes que sofre sem perder o seu sentido de continuidade.

Destarte, o espaço da "performance ritual do canto" (Calame, 1997, p. 62) parece constituir, por excelência, um espaço dialético entre a coletividade humana e a dimensão religiosa ou seja, entre o presente ritual e o passado mítico. Veja-se, nesse sentido, o que diz Vernant:

Enquanto a cidade permaneceu viva, a atividade poética continuou a exercer esse papel de espelho que devolvia ao grupo humano sua própria imagem, permitindo-lhe apreender-se em sua dependência em relação ao sagrado, definir-se ante os Imortais, compreender-se naquilo que assegura a uma comunidade de seres perecíveis sua coesão, sua duração, sua permanência através do fluxo das geraçôes sucessivas. (Vernant, 2006, p. 16).

Contudo, convém ressaltar que essa imagem espelhada e articulada pelo canto permanece enquanto continuum só porque se modifica, não por ser estática. Mitos e ritos atualizam-se no contexto da performance e fornecem, assim, uma imagem coesa da própria coletividade que os compartilha.

Por conseguinte, o ato de canto, que também é ato ritual e de culto (Calame, 1997, p. 62), constitui necessariamente um elemento da dinâmica social no qual os valores e as visōes de mundo dominantes de um determinado grupo são não só criados, mas também recriados constantemente. 
2. Cf. LEACH, E.R.,

"Cabelo Mágico". In: Antropologia. R.D.Matta (org.). Trad. A.Z. Guimarães. São Paulo: Ática, 1983. (p. 141).
E, nesse sentido, o caráter ritual da poesia laudatória de Píndaro parece passível de ser pensado à luz da perspectiva antropológica indicada por Mariza Peirano. Traduzindo de forma livre a definição operativa formulada por Stanley Tambiah (1985), Peirano nos apresenta a seguinte conceituação:

O ritual é um sistema cultural de comunicação simbólica. Ele é constituído de sequências ordenadas e padronizadas de palavras e atos, em geral expressos por múltiplos meios. Essas sequências têm conteúdo e arranjo caracterizados por graus variados de formalidade (convencionalidade), estereotipia (rigidez), condensação (fusão) e redundância (repetição). A ação ritual nos seus traços constitutivos pode ser vista como "performativa” em três sentidos: 1) no sentido pelo qual dizer é também fazer alguma coisa como um ato convencional (...); 2) no sentido pelo qual os participantes experimentam intensamente uma performance que utiliza vários meios de comunicação (...) e 3) no sentido de valores sendo inferidos e criados pelos atores durante a performance. (Peirano, 2003, p. 13).

Assim, mostra-se não só possível como produtiva a abordagem da ode pindárica enquanto sistema performativo, que visa comunicar valores que constituem a cultura específica de uma coletividade, que assim afirma sua identidade social ${ }^{2}$.

Sobre sua morfologia, consideramos que, no que tange a ser "constituído de sequências ordenadas e padronizadas de palavras e atos, em geral expressos por múltiplos meios", o epinício pindárico parece novamente se enquadrar no gênero de manifestação ritual. Com efeito, a linguagem poética parece ser ritual por excelência, expressando-se através de certos padróes métricos e rítmicos, constantes e sequenciais. Embora a história não nos tenha legado dados mais concretos referentes à expressão gestual da poesia comumente designada como lírica grega coral, parece possível supor que a expressáo gestualizada acompanhasse, genericamente, a padronização rítmica sendo por ela orientada, como parece ser comum à dança de modo geral.

O conteúdo dessas sequências são, fundamentalmente, os mitos e sentenças e seu arranjo norteia-se, o mais das vezes, pelo aspecto estético e poético. Assim, os "graus variados de formalidade (convencionalidade), estereotipia (rigidez), condensação (fusão) e redundância (repetição)" articulam-se 
de acordo com as necessidades expressivas e de gênero e com a axiologia manifesta na ode. As convenções, em forma de estruturas paradigmáticas, manifestam-se tanto no nível da performance quanto no das diferentes narrativas, mas a rigidez é relativizada pelo processo exposto, através do qual mito e ritual transcendem o tempo e se atualizam com o presente. A arquitetura das composiçóes apresenta também, de acordo com o poema, níveis diferentes de condensação das sequências significativas e de suas repetiçóes.

Finalmente, a apreciação da ação ritual vista como "performativa" em seus traços constitutivos, parece mostrar-se extremamente aplicável ao que se mostra possível designar como "poesia-ritual" de Píndaro.

Peirano, como citado, aponta três sentidos pelos quais a ação ritual pode ser vista como "performativa". Em primeiro lugar, "no sentido pelo qual dizer é também fazer alguma coisa como um ato convencional".

Isto pode ser compreendido segundo a perspectiva de que aquilo que é dito na performance ritual implica a geração de um fato social. Dizer é fazer socialmente na medida em que o canto, através das estratégias citadas da etiologia e do ritual, reconfigura a disposição da realidade coletiva através de sua enunciação. O mecanismo verbal, uma vez posto em ação pelo ritual em um contexto performativo, desencadeará, necessariamente, uma alteração, reconfirmação ou negação de um fato ou valor prático da comunidade.

O segundo sentido pelo qual, segundo Peirano, a ação ritual deve ser vista como performativa é aquele "pelo qual os participantes experimentam intensamente uma performance que utiliza vários meios de comunicação" ${ }^{\text {. }}$. Sobre esse sentido em específico, pode-se deduzir, a partir da consideração dos dados performáticos, o intenso efeito que a execução de um epinício, conjugando ao mesmo tempo a poesia, o canto e a dança, produzia sobre seus espectadores. E, além disso, se o aspecto estético é recebido com tal intensidade, com a mesma força pressupóe-se que ele se imponha como catalisador nos outros desdobramentos da ação, por exemplo, na criação, recriação ou reforço de valores compartilhados pela coletividade e assimilados no ritual como experiência de ordem religiosa.
3. PEIRANO, 2003, p. 13.

4. Ibidem. 
6. ELIADE, M. Aspectos do Mito. Trad. M.Torres, Lisboa: Ediçôes 70, orig. 1963 , p. 124

7. Idem, p. 125. .
Por fim, segundo Peirano, a ação ritual é performativa "no sentido de valores sendo inferidos e criados pelos atores

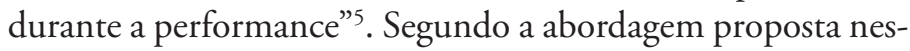
te trabalho, embora o rito atualize valores e potencialidades que já existem na comunidade à qual pertence (PEIRANO, 2001), vê-se que, dentro de certo limite, sentidos são criados e ampliados ou (num sentido mais religioso) revelados aos receptores pelo processo, pois o discurso poético, que se pronuncia lançando máo do mito ritualmente orquestrado, opera também e necessariamente num sentido criativo.

Mircea Eliade sublinha o papel criativo e imaginativo no processo de renovação de uma tradição mitológica:

(...) Os vários especialistas do sagrado, desde os xamãs até os bardos, acabaram por impor nas respectivas coletividades pelo menos algumas de suas visōes imaginárias. Evidentemente que o "êxito" dessas visóes dependia dos esquemas já existentes: uma visão que contrataste radicalmente com as imagens e os cenários tradicionais corria o risco de não ser facilmente aceite ${ }^{6}$.

E ainda:

(...) Mas porque a cultura arcaica gira em torno de mitos, e estes últimos são continuamente reinterpretados e aprofundados pelos especialistas do sagrado, todo o conjunto da sociedade é conduzido para os valores e significados descobertos e veiculados por esses indivíduos 7 .

Embora a associação de Píndaro com um desses "especialistas do sagrado" de Eliade seja deveras sedutora, pelas reflexôes apresentadas deduz-se que atribuir a responsabilidade e o papel de elaborar as renovaçóes dos mitos e rituais àquele que os manipula, através do canto, constitui uma compreensão equivocada, nomeadamente, por prescindir ingenuamente da dinâmica social do processo.

É evidente que podemos admitir como uma das funções que o canto exerce na sociedade a perspectiva filosófico-religiosa, mantendo e criando valores, instruindo e celebrando, atuando como princípio dinâmico na articulação da identidade coletiva, uma vez que, através do canto dos poetas, o mundo dos deuses distante e terrível, envolto em uma bruma 
sempiterna de mistério, revela-se de forma familiar e acessível, cognoscível, enfim, à comunidade que, ordinariamente, necessita compreender sua relação com o divino para construir o sentido mítico-religioso do mundo.

Por outro lado, verifica-se que a forma com que mito e ritual atuam no contexto performativo deve ser entendida em sua dinâmica social para que possa fazer sentido enquanto meio de manutenção e perpetuação dessa mesma sociedade. A etiologia e o processo ritual conjugam a mesma estratégia de projetar-se como algo vinculado ao passado mítico para construir sua autoridade pretensamente inquestionável e assim atuar como elementos de acomodação das mudanças presentes, integrando-as à imagem identitária que a coletividade constrói de si mesma. Inerente ao processo é o fato de que a "tradição" não é simplesmente renovada por um "especialista", que nela introduz seus vislumbres particulares e sua acepção religiosa pessoal, mas seu papel é o de assimilar à tradição que veicula as demandas da conjuntura presente que observa.

Por fim, verifica-se que o epinício pindárico acaba por constituir-se como uma espécie bem definida de celebração ritualizada, cuja fonte e autoridade provêm, nomeadamente, dos mitos, não apenas enquanto elementos enunciativos, mas, sobretudo, enquanto concepção de mundo. O pensamento mítico aqui é a forma de acesso e de relação com a realidade, é o meio pelo qual a comunidade se projeta no cosmos e busca construir seu espaço ontológico, vinculando-se ao sagrado. Mas esse processo só se concretiza através da experiência singular da performance ritual.

A Olimpica I de Píndaro foi composta para celebrar a vitória que Hierão, tirano de Siracusa, obteve com seu cavalo Ferênico (literalmente "o que traz a vitória") na corrida de cavalos dos Jogos Olímpicos de 476 A.E.C. Em Alexandria, Aristófanes de Bizâncio escolheu-a como primeira das odes pindáricas dedicadas a vencedores olímpicos, provavelmente, porque o poema contava o mito de Pélops, o primeiro vencedor de uma corrida de bigas em Olímpia e inaugurador lendário dos jogos (RACE, 1997).

Sobre a vitória celebrada de Hierão, o canto projeta o mito de Pélops que, trabalhado pela linguagem poética diga-se, ritual por excelência -, surge como paradigma que justifica e sacraliza a ocasião, que se perfaz como reatualização cíclica de um modelo primordial. 
Se, a partir do texto do epinício, pode-se abarcar os diferentes sentidos suscitados pelo discurso, lamentavelmente, a abordagem da ode pindárica, no que tange à sua dimensão performática, apresenta-se, inevitavelmente, limitada pela ausência daqueles elementos que seriam indispensáveis para que pudéssemos compreendê-la em sua totalidade: a música e a dança.

Com efeito, a dimensão musical da ode, presumivelmente, constituir-se-ia em um elemento fundamental para se conjugar em uma estrutura esteticamente homogênea, o discurso verbal e a expressão corporal. Assim sendo, nossa leitura precisa mostrar-se consciente de que, se por um lado, não temos acesso integral ao conjunto, por outro, a análise deve manter a consciência da ausência sempre presente. Se a lacuna limita, o ignorar a sua existência poder-se-ia mostrar ainda mais limitador. Isso posto, limitaçóes e possibilidades convivem na leitura, na construção de sentidos e nas reflexóes desenvolvidas. $\mathrm{O}$ exame do texto pode se revelar náo como fonte de respostas definitivas, mas enquanto edificação de possibilidades.

Lucia Athanassaki (2004) opõe às limitaçóes da reconstituição da prática performativa as possibilidades da análise dêictica e, sobre esse aspecto da Olimpica I, afirma:

The First Olympian Ode is, deictically, Pindar's most intriguing composition. It represents an exception to the epinician practice of Pindar and Bacchylides, who frequently dramatize contemporary and mythical scenes successively in the course of the same performance, but do not blur the boundaries between the different spatio-temporal realms. The First Olympian for$\mathrm{ms}$ a remarkable exception to this practice: through a variety of deictic devices, the epinician speaker creates the illusion of stepping temporarily into mythical time and space, playing, in turn, the roles of Pelops's interlocutor and eyewitness to events that occurred at a remote time. (Athanassaki, 2004, p. 319).

O epinício parece assim realizar uma dissolução da fronteira entre o passado mítico e o presente da performance que se notabiliza, inclusive, pela própria articulação dêitica da ode.

A abertura do epinício dá-se por um preambulum que, através de um quadro de imagens poéticas, sugere de maneira intensamente visual a concepção da excelência: 
O melhor é a água, enquanto o ouro, como o fogo brilhando na noite, distingue-se mais que a riqueza exaltadora de homens.

Se jogos celebrar

desejas, caro coração,

não mais cálido que o sol

luzindo de dia outro astro

mires no ermo éter,

nem uma competição superior à de Olímpia cantaremos.

(v. 1-7; Tradução própria).

O grandiloquente priamel da primeira estrofe converge para a imagem de Hierão que surge estrategicamente no $12^{\circ}$ verso. Aqui, convém que se observe a maneira como Píndaro refere-se ao laudandus e a um banquete (presumivelmente fictício ${ }^{8}$ ) organizado em seu palácio:

...ao rico e ditoso lar de Hierão,

o qual detém o cetro da justiça na fecunda

Sicília, colhendo os píncaros de todos os êxitos,

e gloria-se também

na fina flor da música,

com que nós, varôes, folgamos

amiúde em sua mesa amiga.

(v. 11-17; Trad. própria).

Essa referência, com efeito, transmite duas caracterizaçôes complementares de Hierão: fala-se de seu poder (político) e de sua hospitalidade. Hierão é aquele que "detém da justiça o cetro na fecunda/ Sicília”, mas também é aquele que oferece continuamente a generosidade de sua "mesa amiga".

Compreende-se que a cena descrita na passagem situada no verso 14-ss. da Olimpica I configura um quadro ficcional cujo propósito encomiástico reside em colaborar na construção de uma imagem específica do laudandus, qual seja, a de um governante que além da caracterização majestosa descrita nos versos 12-13, apresenta-se também como alguém próximo, acessível e acolhedor. Nota-se que Píndaro parece elogiar o tirano como a um seu igual, um louvor de aristocrata para aristocrata. O quadro que ilustra uma poética (fictícia) situação da performance do epinício descreve uma celebração na
8. Como demonstrado por Budelmann (2012, p. 185), evidências que vinculem a performance dos epinícios a um contexto de simpósio são pouco convincentes.

A passagem deve antes ser pensada como um quadro ficcional, simulando uma cena de simpósio e náo como indicativa da performance real do epinício. Assim:"Some epinicians, not least those just listed, clearly go to some length to evoke the symposion, but they do not usually present themselves as sympotic performances. The issue here is not just the difficulty of relating the symposion references to real performances. That question - when is Pindar's language metaphorical and when can it be taken as a reliable guide to real contexts? - was the crux of the debates over epinician performance and the komos: is 'this komos' a metaphorical way of saying 'this chorus' (Carey/ Burnett) or does it refer to a real komos (Heath/ Lefkowitz)? In the case of the symposion, one does not even get to pose the question. With the symposion, epinicians rarely go as far as enkomia go quite regularly, and rarely go as far as they themselves go with the komos.

Epinicians repeatedly claim to be performed as part of a komos (e.g. 'this komos' at Ol. 4.9, 8.10, Pyth. 5.22)

but hardly ever as part of a symposion." (Budelmann, 2012, p. 185). 
9. Esse evento público não deve ser tomado como um simpósio strictu sensu. Nesse sentido, Budelmann (2012, p. 187) argumenta que as evidências disponíveis indicam que a performance do epinício deve ser antes pensada como tendo lugar num komos e não num simpósio: “(..) my central claim in this section has been that epinician does indeed maintain a relationship with the symposion, but that this relationship is vague and complex, more vague and complex than some recent scholarship allows. Whereas a number of enkomia place their own performance at a symposion, epinicians do so very rarely. Instead, the context in which several epinicians purport to be performed is the komos, a type of occasion that has obvious sympotic links, but is not confined to the narrow indoors world of the symposion. What is more, the symposion is only one of several kinds of feasts or banquets mentioned in epinicians." "mesa amiga" de Hierão embora, presumivelmente, o epinício tenha sido performatizado em um grande evento público 9 (CAREY, 2009, p. 32-38). O espaço real da performance é ressignificado poeticamente criando-se, assim, uma moldura ritual que demarca o espaço "sacralizado", leia-se social e simbolicamente significativo, a partir do qual o canto opera sobre a realidade coletivamente compartilhada.

Embora esta situação ritual possa ser entendida genericamente como secular, verifica-se um entrelaçamento entre os símbolos religiosos e sociais, através dos quais o poder da performance opera sobre os ânimos da coletividade.

Através das múltiplas linguagens de que a performance de uma ode lança mão em sua execução ritualizada, sentidos são criados, recriados, propostos e insinuados aos expectadores. Esses sentidos são processados em uma caracterização estética, não puramente objetiva. $\mathrm{O}$ lirismo da música desperta, a efervescência da dança contagia, a grandiloquência das palavras encanta, enquanto a sacralidade do mito desperta no homem o sentimento de veneraçáo e comunhão com o divino. Por fim, todos esses elementos atuam em conjunto na tessitura do que seria uma espécie de "retórica" da performance.

Segundo Gilbert Lewis o ritual conjuga, expressivamente, várias linguagens em sua execução de uma maneira análoga à performance teatral e essa característica define a forma como ambos são "sentidos" e não "compreendidos" pelo espectador. Dessa forma:

When we watch a play we are affected by the words of the text, the gestures, movements and intonation of the actors, the costumes and the decor, and the lighting. The play is a contrivance of great complexity in which most varied stimuli work on us to produce or spark off a complex response. The varied stimuli of light, colour, gesture, movement, voice, language work on us in different ways to set up this complex response. As Mounin (1970, p. 92) suggests for the theatre, it may be more helpful to think generally of what happens in ritual in terms of stimulation rather than communication. (LewIs, 2007, p. 33-34).

É essa "estimulação" o resultado final, a "resposta complexa" que a performance ritual suscita através dos diferentes recur- 
sos expressivos que conjuga e que se somam numa intrincada máquina insinuadora de sentidos esteticamente trabalhados.

Se a performance é expressa em termos estéticos complexos, o que se pode compreender acerca de sua resposta é que ela é assimilada em termos sensoriais e emocionais, e a adesão que produz esquiva-se, em certa medida, de uma potencial refutação lógico-racional. Assim, quando o elogio a Hierão é traduzido em termos estéticos e performatizados, a plateia o recebe não como ideia, mas como sentimento que contamina.

Segundo Lewis:

But the 'meaning' of a ritual performance or a play is much further off from the meaning of a purely linguistic message than it is from the 'meaning' of an event. We interpret a ritual or the performance of a play rather in the way we interpret an event at which we are present or in which we take part: we do not 'read' the event as we experience it or as we reflect on it; we do not 'decode' it to make sense of it or understand it. We are affected by it. It may set us thinking. (LEwis, 2007, p. 34).

A performance ritual nos "afeta" e, em um segundo momento, o nosso pensamento é também contaminado por ela, na medida em que a adesão da mensagem sugerida é eficazmente empreendida.

Em relação a presente ode, o contexto pode nos dar algumas sugestôes significativas quanto à representatividade do canto laudatório performatizado de Píndaro dirigido a um tirano como Hierão. Daisi Malhadas (1976) afirma que, segundo as informaçóes legadas por Diodoro, Hierão, enquanto tirano, mostrava-se ambicioso e violento, fato que levava muitos siracusanos a desejarem depô-lo. Poderia parecer, a princípio, que a forma mais eficaz de induzir a comunidade a uma maior aceitação de Hierão seria valer-se da performance para elogiá-lo diretamente. No entanto, os epinícios de Píndaro assentam-se muito mais sobre narrativas míticas e recursos poéticos do que sobre elogios diretos ao vencedor. Entretanto, as características próprias de como uma performance expressa seu conteúdo, bem como a dinâmica mito-ritual com a qual opera, pode fazer com que um canto pindárico que objetiva elogiar um homem como Hierão tenha, da maneira como se apresenta, um eficaz reflexo 
na constituição e reparação de uma boa imagem do tirano frente à comunidade que o mesmo governa. Neste sentido, pode-se depreender que a projeçáo implícita do mito de Pélops sobre a figura histórica de Hierão na Olímpica I é sobremodo mais eficaz na capacidade de aumentar a sua popularidade e consequente aceitaçáo do que fazer-lhe apenas elogios explícitos. De acordo com Kowalzig:

(...) in the Greek world, as in many other cultures, the sense of community invoked by ritual is that of a religious community defining itself by its relation to the past, and the social and power relations between participants are staged as those deriving from a past. (KowaLZig, 2007, p. 40).

Com efeito, a associação da imagem do laudandus com a do herói mítico decorrente da ode contagia a imagem pública de Hierão com o status de autoridade tradicional que é atribuído ao mito.

A incontestabilidade da autoridade do mito performatizado manifesta-se em duas instâncias: em primeiro lugar porque o mito e a tradição ritual vinculam-se ao "tempo das origens" e à dimensão desse "passado sagrado" que estabelece os paradigmas religiosos que definem a sociedade e, em segundo lugar, porque as inovaçóes introduzidas nessa tradição são efetuadas na performance, percebidas esteticamente e endossadas pela dimensão sensorial-emocional.

A vinculação entre Hierão e Pélops na ode é elaborada de forma tăo natural que parece decorrer de uma dedução óbvia da realidade, mas configura, no entanto, uma estratégia narrativa capaz de conduzir do presente ritual para o passado mítico quase que imperceptivelmente aqueles que se encontram imersos no contexto performático:

...de Siracusa o cavaleiro rei. Lampeja-lhe a glória na colônia farta em heróis do lídio Pélops. (v. 23-24; Tradução própria).

Köhnken (1974) ressalta o paralelismo existente entre a

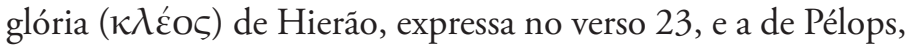
nos versos 93-5, que demarcam textualmente a associação cor- 
respondente entre o laudandus e o herói mítico que lhe serve por paradigma no canto:

The present Olympic success is pointed out at the beginning as well as the end of the mythical narrative which forms the body of the ode: Pindar starts his narrative in line 23 with the

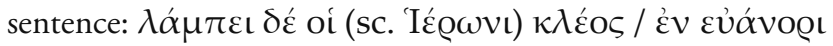
$\Lambda v \delta о \tilde{~} \Pi \varepsilon \dot{\lambda} \lambda$ то

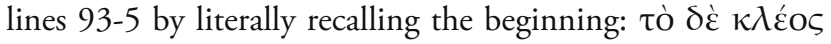

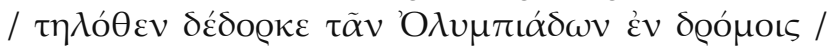

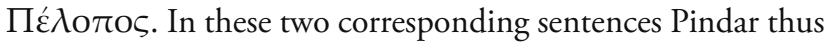
puts Hieron's and Pelops' glory on the same level: they are

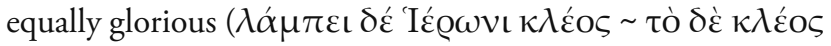

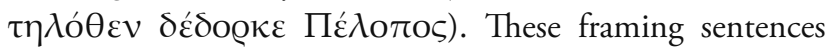
('Hieron's glory shines in Olympia, the city of Pelops' and 'far shines the glory of Pelops in the Olympic races') show that Hieron's recent victory in the horse-race is in a line with the success which Pelops won in a famous mythical horse-race: Pelops, who is called by Tyrtaios (fr. 9, 7 D.) 'the most royal among the mythical hero-kings' and who is therefore an obvious counterpart to the most princely of contemporary kings, Hieron of Syracuse. (p. 199-200).

O mito irrompe assim no canto e contagia a figura secular de Hierão com a sacralidade mítica de Pélops:

Pelo qual se enamorou o poderoso sustentáculo da terra, Poseidon, quando do imaculado caldeirão

Cloto o retirou, com a brilhante espádua de marfim ornada. (v. 25-28; Tradução própria).

$\mathrm{Na}$ abordagem dada ao mito de Tântalo e Pélops pelo poeta na Olímpica I, rejeita-se a versão segundo a qual Tântalo convidara os deuses para um banquete em que lhes servira as carnes do próprio filho, Pélops, e no qual Deméter chegara a comer um pouco de seu ombro:

Filho de Tântalo, infenso a meus precedentes, de ti falarei: quando teu pai convidou para o digníssimo festim na amada Sípilo, 
oferecendo um recíproco banquete aos deuses, foi então que o Ilustre-Tridentino te arrebatou, dominado no peito pelo desejo, e sobre auríferos corcéis, conduziu-te à altíssima morada do mui honrado Zeus, para a qual ulteriormente foi também Ganimedes a Zeus para o mesmo ofício.

E como invisível estavas, nem, os homens muito buscando, à tua mãe trouxeram-te, logo um dos invejosos vizinhos contou em segredo que no auge da fervura d'água ao fogo com faca te retalharam os membros e sobre as mesas por fim as tuas carnes repartiram e comeram. (v. 36-51).

Athanassaki chama-nos a atenção para a opção narrativa utilizada para o mito de Pélops que parece incrementar ainda mais a credibilidade da versão mítica "verdadeira" ao colocar, narrativamente, o locutor (e consequentemente, toda a audiência da performance) como testemunha ocular dos fatos narrados:

In odes that contain mythical narratives, the epinician speaker is ordinarily an external omniscient narrator vis-à-vis the myth. As an omniscient narrator external to the myth, he narrates mythical events either in his own persona from beginning to end, or partially in his own persona and partially through the reported discourse of mythical characters, or else as an external omniscient narrator in dramatized mythical narratives. As an external omniscient narrator of mythical events, the epinician speaker does not offer any indications that suggest a shift in his localization, which remains by implication at the hic et nunc of the epinician performance. An implicit spatial shift may take effect in cases of dramatized narratives, however, where the speaker adopts a role analogous to that of a tragic messenger, or in open-ended narratives in which the poetic voice imperceptibly joins the reported divine or mantic discourse. Yet remarkably in the First Olympian Ode, the epinician speaker narrates a substantial part of the myth as an eyewitness, explicitly suspending, for a while, his localization in Syracuse. (AtHANASSAKI, 2004, p. 325-326). 
Segundo Píndaro, Pélops foi raptado por Poseidon que dele enamorara-se num cenário claramente paralelo ao contexto de práticas comuns de iniciação de efebos à vida adulta ${ }^{10}$.

$\mathrm{Na}$ narrativa apresentada, Píndaro estabelece ainda um paralelo explícito de sua versão do mito de Pélops com o rapto de Ganimedes (v. 43-45) que, tendo sido raptado por Zeus por conta de sua beleza corrobora, também, para justificar a versão do rapto de Pélops, eroticamente motivado, por Poseidon, que Píndaro nos apresenta.

Embora Píndaro rejeite uma versão do mito julgada como "falsa", ele indiretamente a veicula já que a narrativa coloca em primeiro lugar a evidência do ombro de marfim de Pélops (v. 27) que lhe teria sido colocado justamente em substituição ao original que fora comido na versão do mito que Píndaro pretende negar.

Embora se possa imaginar que Píndaro retifique o mito por adequá-lo às suas visóes pessoais, Gregory Nagy argumenta de maneira diferente, demonstrando que o que está em jogo aqui é mais uma vez o mecanismo estratégico do mito etiológico e do ritual, trabalhando no sentido de projetar, em uma tradição que se quer remota, as condiçóes, demandas e fatos do presente:

I shall argue that the "substitution" as represented in Olympian 1 is in fact a poetic expression of a preexisting fusion of two myths, where the earlier myth is officially subordinated to but acknowledged by the later myth. Furthermore, I shall argue that the relative earliness and lateness of these two myths has to do not with any innovation by Pindar himself but rather with the historical sequence of the accretion of traditional myths officially associated with the complex institution of the Olympics. (NAGY, 1986, p. 71-72).

Nagy (1986), baseado em Burkert, afirma que a rejeiçâo de uma versão do mito em prol de outra, ou antes, a fusão dos dois, dá-se porque o primeiro mito, que narraria o banquete terrível em que Tântalo servira as carnes do próprio filho aos deuses, estava relacionado a uma etiologia anterior dos Jogos Olímpicos, em que a corrida a pé (stadium) era a modalidade principal. O sacrifício oferecido no altar de Zeus em um precinto dedicado a Pélops pelo vencedor dessa modalidade estava relacionado ao sacrifício de Pélops no banquete pelas mãos do próprio pai: 
11. Cf. Nagy (1986, p. 73-74): "Each founding of a Greek athletic festival was apparently motivated by at least one myth that told of a hero's death. In the case of the four great panHellenic Games, the main foundation myths are as follows: Olympian Games (Olympics), founded by the hero Pelops in compensation for the death of Oinomaos; alternatively, founded by the hero Herakles, in compensation for the death of his greatgrandfather, Pelops".
Specifically, as Burkert shows, the myth of the slaughter of Pelops must have been an aition correlated with the ritual of the slaughter of the black ram at the precinct of Pelops. In the myth, the only part of the dismembered Pelops that was actually eaten by the gods was the hero's shoulder, consumed by Demeter, which was later replaced with an ivory piece in his reintegrated body. Here we see a specific aition for the ritual reverence of the ivory shoulder-blade of Pelops, a larger-than-life cult object on display at Olympia, in that the shoulder-blade of the slaughtered hero is analogous to the shoulder-blade of slaughtered rams: in ancient Greece, as Burkert points out, "a ram's shoulder blade played a special part in the sacrifice of a ram.” (NAGY, 1986, p. 80).

A nova versão do mito é inserida para adaptar a tradição etiológica anterior à realidade presente dos Jogos Olímpicos no início do quinto século. Visto que a corrida de carros de cavalos era a competição central e de maior prestígio na época de Píndaro, disputada apenas por aristocratas poderosos que tinham condiçóes de arcar com os custos (o próprio Hierão seria vencedor nessa modalidade em 468, alguns anos depois da vitória celebrada na Olimpica I), a etiologia dos Jogos adaptou-se ao contexto de então, em um claro exemplo da articulação entre mito, ritual e performance (exposta no capítulo 2).

Com efeito, cada um dos grandes festivais atléticos pan-helênicos tinha, por motivação primordial, um mito sobre a morte de um herói, constituindo-se, originalmente, de jogos funerais ${ }^{11} . \mathrm{Na}$ Olimpica I o mito etiológico relacionado à fundação dos jogos é reformulado em termos da realidade contextual de sua produção e performance. Desloca-se o aition da corrida a pé e do mito da morte de Pélops para a corrida de carros de cavalos e o mito da morte de Enómao. No entanto, as duas versóes, além de conviverem, se interpenetram na narrativa da ode e, embora Píndaro se refira às duas versóes em termos de "verdadeira e falsa”, a sua rejeição de uma não a exclui, antes a subordina à outra, o que remete à própria escala de importância das modalidades da competição (corrida a pé e corrida com carros de cavalos) que a reformulação dos mitos representa, prestando-se ainda, como o próprio poeta diz, a um retrato dos deuses mais piedoso e adequado, um retrato mais luminoso do divino. Entretanto, não podemos ignorar que o ombro de marfim de Pélops está lá, desde o início da seção mítica do canto, a relembrar a versão do banquete terrível e canibalesco que se quer olvidar. 
Assim, a performance ritual da Olimpica I de Píndaro, com sua versão do mito de Pélops, expressa a remodelaçáo de outro evento ritual, os Jogos Olímpicos, cuja conjuntura está, por sua vez, refletindo, em seu deslocamento da modalidade principal, as condiçóes sociais presentes que lhe contextualizam. A manifestação da poesia-ritual, aliando o processo verbal e o performativo, expóe a vinculação do contexto circunstancial da execuçáo do canto ao mito, reelaborando-o.

As potencialidades específicas do canto são oriundas de sua própria natureza que é capaz de reelaborar os mitos, já que não pertence ao universo cristalizado da escrita, mas à fluidez da performance, conjugando sempre, dialeticamente, presente e passado em sua equação. Além disso, é o caráter performático do canto que possibilita que esse passado mítico seja reelaborado no presente, materializando na plasticidade do desempenho a presença divina e possibilitando à comunidade que o compartilha, a comunhão com o sagrado.

É o caráter ritual da execução do epinício que possibilita esta presença divina que se manifesta na performance, caráter este que, para a leitura da ode enquanto texto escrito, retido na imobilidade da letra e da folha que o abriga, encontra-se inevitavelmente perdido. No entanto, quando retomamos a condição performática do epinício, ficam visivelmente explícitos os desdobramentos significativos que a dialética estabelecida entre mito, ritual e performance estabelece.

Assim, embora a versão do mito de Pélops que Píndaro nos apresenta seja historicamente recente e conviva narrativamente com a versão mais antiga, essa "verdadeira história" é, através da performance e seu aspecto ritualístico, apresentada ao público como verdade tradicional e original, enraizada no passado mítico.

É claro que a eficácia social e política do tipo de celebração a que pertence uma canção de louvor não pode ser ignorada, pois está intrinsecamente aliada ao sentido religioso de que o canto poético se mostra investido e, ao estabelecer uma vinculaçáo do hic et nunc da conjuntura histórica em que está inserido com a realidade mítico-religiosa, o canto-ritual atua, também, como mecanismo social de manutenção.

Mas essa consideração não deve ser tomada de modo unilateral, pois o poeta aqui não é um simples funcionário do sistema, trabalhando em função da adequação da tradição e consequente manutenção do status quo. Devemos sopesar que a excelência dos 
homens que Píndaro imortaliza pelo canto só pode vir a ser com a anuência dos deuses, e sempre se preservando da desmesura que lhes incita à ira. Essa dependência em relação aos deuses fica nítida na fala dirigida a Hierão nos versos 106-110:

\author{
Um deus guardião trabalha, \\ cuidadosamente, Hierão, \\ por tuas aspiraçóes. E se náo logo te deixa, \\ ainda mais docemente espero \\ celebrar com o célere carro... (Tradução própria)
}

O louvor de Píndaro a excelência é frequentemente balizado pelo apontamento das limitaçóes humanas, e de sua dependência em relação ao sagrado. Afinal, o próprio canto que imortaliza os excelentes feitos (e é o mais próximo que um homem pode chegar de transcender sua finitude) tem sua origem no dom sagrado das Musas.

Além disso, se Píndaro se vale de seu poderio poético e da eficácia de sua performance ritual para engrandecer e preservar a memória de um ilustre aristocrata e seus antepassados, também faz o mesmo com a memória de toda a coletividade cívica a que ele pertence (CAlame, 1997, p.62), na medida em que os mitos, lugares e costumes culturais eternizados pelo seu canto formam a identidade social de um determinado agrupamento humano, o que eles detinham de mais precioso e sagrado. Assim, Kowalzig argumenta que:

Greek rituals, however, public or not, had little to do with indoctrination or repression through an authoritative ritual that includes drilled modes of behaviour or the engendering of mass enthusiasm. On the contrary, the dispersed Greeks had much power to be negotiated, and little authority to focus it. (...) Ritual in Greece will have been a form of social control as in many other places but there is a multiplicity of highly flexible mutual social controls between the parts of a community that is expressed in ritual. (Kowalzig, 2007, p. 54).

Píndaro, porquanto trabalhe o seu canto com o objetivo de louvar Hierão, também lhe fará prescrições gnômicas e lhe advertirá em relação aos malefícios do excesso. Isso se evidencia na ode seja diretamente através da gnome: 
Doutros modos outros são grandes.

Mas o cume eleva-se para

os reis. Não vises além.

(v. 113-114; Tradução própria).

...ou seja através do paradigma mítico que, em contraste com a referência posi tiva de Pélops, manifesta-se como exemplo de desmesura em Tântalo:

E se de fato algum homem mortal os olímpios sentinelas estimaram, esse foi Tântalo.

Mas, no entanto, de digerir a imensa fortuna não foi capaz...

(v. 54-56; Tradução própria).

Nos versos finais (115-116), o discurso estabelece uma dialética entre os vencedores ( $v \iota \kappa \alpha \phi o ́ @ o \iota \varsigma)$ e o poeta, que é proeminente por sua sabedoria ( $\pi$ @ó $\phi \alpha \nu \tau o v$ бoфí $\alpha$ ), em uma espécie de relação de reconhecimento mútuo: se um vencedor como Hierão só tem seu feito vertido em glória perene pelo poder eternizador do canto, por outro lado o poeta busca ser reconhecido por sua grandeza "artística":

Que tu possas por teu tempo nas alturas caminhar,

e eu táo somente a vencedores

associar-me, preclaro em minh' arte

junto aos Helenos em toda parte.

Ao tentarmos delinear os contornos mito-rituais do canto pindárico, debruçamo-nos sobre a problemática da recepção ativa dele pela coletividade que o compartilha bem como das interaçóes de poder e influência que nele se conjugam. $\mathrm{O}$ mito surge assim perante os nossos olhos, despido de sua moldura empoeirada de papel e tinta e, como é próprio de sua natureza, como um discurso vivo e interativo, relacionando-se dialeticamente com a sociedade que lhe engendra.

O que se delineia nesse horizonte possível é a sugestão de uma compreensão mais ampla e profunda da poesia pindárica. Ela é elogio e poesia, música e dança, sabedoria e religiáo, mito e rito. 


\section{REFERÊNCIAS BibLIOGRÁFICAS}

ATHANASSAKI, Lucia. "Deixis, Performance, and Poetics in Pindar's First Olympian Ode". Arethusa 37, no 3 (2004). The Johns Hopkins University Press. (p. 317-341).

BUDELMANN, F. (Ed.). THE CAMBRIDGE COMPANION TO GREEK LYRIC. New York: Cambridge University Press, 2009. . "Epinician and the symposion. A comparison with the enkomia". In: AGÓCS, P.; CAREY, C.; RAWLES, R. (Ed.). Reading the Victory Ode. New York: Cambridge University Press, 2012.

CALAME, Claude. "Entre narrativa heróica e poesia ritual: o sujeito poético que canta o mito". Letras Clássicas/ Dep. de Letras Clássicas e Vernáculas 1 (1997). São Paulo: Humanitas/ FFLCH/ USP, 1997.

ELIADE, Mircea. Aspectos do Mito. Trad. Manuela Torres. Rio de Janeiro: Ediçōes 70, 1989.

KOWALZIG, Barbara. Singing for the Gods: Performances of Myth and Ritual in Archaic and Classical Greece. Oxford: Oxford University Press, 2007.

LEWIS, Gilbert. Day of Shining Red, an essay on understanding ritual. New York: Cambridge University Press, 2007.

MALHADAS, Daisi. Odes aos principes da Sicília. Araraquara: UNESP, Faculdade de Filosofia, Ciências e Letras de Araraquara, 1976.

NAGY, G. "Pindar's Olympian 1 and the Aetiology of the Olympic Games". Transactions of the American Philological Association, 116. The Johns Hopkins University Press, 1986. (p. 71-88).

PEIRANO, Mariza. Ritudis ontem e hoje. Rio de Janeiro: Jorge Zahar Ed., 2003.

"Rituais como estratégia analítica e abordagem etnográfica”. In: PEIRANO, Mariza (Org.). O dito e o feito: ensaios de antropologia dos rituais. Brasília: Relume Dumará, 2001.

PINDAR. Olympian Odes, Pythian Odes. Edited and translated by William H. Race. Cambridge: Harvard University Press, 1997 VERNANT, J.P. Mito e Religião na Grécia Antiga. Trad. Joana A. D’Avila Melo. São Paulo: Martins Fontes, 2006.

Recebido em agosto de 2012

Aprovado em agosto de 2013 